\title{
The quest for the optimal surgical management of tricuspid valve endocarditis in the current era: a narrative review
}

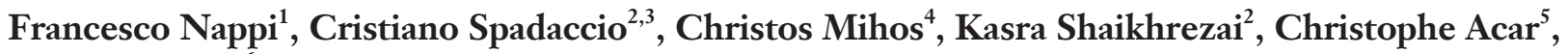 \\ Marc R. Moon ${ }^{6}$
}

${ }^{1}$ Department of Cardiac Surgery, Centre Cardiologique du Nord de Saint-Denis, Paris, France; ${ }^{2}$ Department of Cardiac Surgery, Golden Jubilee National Hospital, Glasgow, UK; ${ }^{3}$ Institute of Cardiovascular and Medical Sciences, University of Glasgow, Glasgow, UK; ${ }^{4}$ Echocardiography Laboratory, Columbia University Division of Cardiology, Mount Sinai Heart Institute, Miami Beach, FL, USA; ${ }^{5}$ Department of Cardiovascular Surgery, Hospital de la Salpetriere, Paris, France; ${ }^{6}$ Department of Cardiac Thoracic Surgery, Washington University School of Medicine, Saint, Louis, Missouri, USA

Contributions: (I) Conception and design: F Nappi, C Spadaccio; (II) Administrative support: None; (III) Provision of study materials or patients: None; (IV) Collection and assembly of data: F Nappi; (V) Data analysis and interpretation: F Nappi, C Spadaccio; (VI) Manuscript writing: All authors; (VII) Final approval of manuscript: All authors.

Correspondence to: Francesco Nappi, MD. Department of Cardiac Surgery, Centre Cardiologique du Nord, 36 Rue des Moulins Gémeaux, 93200 Saint-Denis, Paris, France. Email: francesconappi2@gmail.com.

\begin{abstract}
Tricuspid valve endocarditis (TVE) is a growing concern with increasing rates and mortality burden. The currently changing etiology, the antibiotic resistance and the raise in iatrogenic causes as with implantable cardiac devices [cardiac implantable electronic device (CIED)], represent a challenge for the management of these patients. The progressively widespread use of CIEDs is adding to the more commonly known intravenous (IV) drug abuse in the list of causes. Treatment strategies include medical therapy alone or surgery. From the surgical standpoint tricuspid valve repair, replacement or the staged procedure of valvectomy as bridge to replacement are available options. Treatment of endocarditis related to implantable device is another expanding field which requires a coordinated action with microbiologists in consideration of the microorganism antibiotic resistance. This review summarizes the currently available evidences on TVE including surgical indications, timing of interventions and technical considerations. The conflicting results of the available observational evidences and the non-unanimous consensus on many aspects of TVE impede to reach a definitive conclusion regarding the best management strategy and demands for randomized studies in this field.
\end{abstract}

Keywords: Tricuspid valve infective endocarditis; intravenous drug abuser (IVDU); cardiac implantable electronic devices treatment and management

Submitted Jun 13, 2020. Accepted for publication Jul 10, 2020.

doi: $10.21037 /$ atm-20-4685

View this article at: http://dx.doi.org/10.21037/atm-20-4685

\section{Introduction}

Tricuspid valve endocarditis (TVE) is defined as an infectious process of some portion of one or more leaflets of the tricuspid valve (TV). In developed countries, it is the most common cause of acute tricuspid regurgitation (TR). In a study of the Oxford University $(1,2)$, the prevalence of TVE ranged among $5-10 \%$ of cases of heart valve endocarditis (HVE). Risk factors are intravenous drug use, cardiac device implant, central venous catheters, HIV, and congenital heart disease (CHD) $(3,4)$.

Despite being common among intravenous drug abusers (IVDUs), the increasing proportion of patients with cardiac implantable electronic devices (CIEDs) make this etiology a distinctive characteristic of TVE in the $21^{\text {st }}$ century when compared to the $20^{\text {th }}(5,6)$. The natural history of 


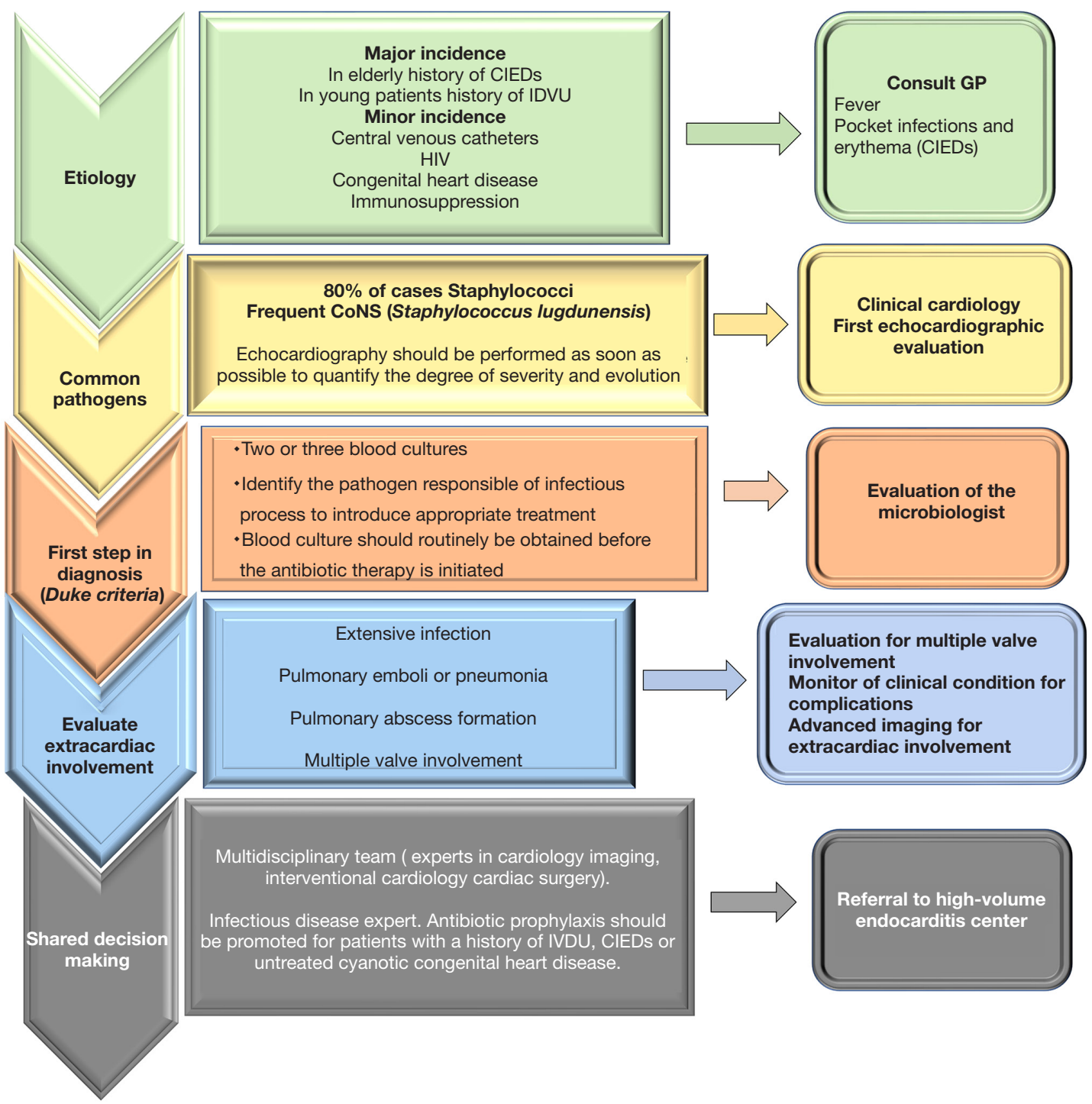

Figure 1 Summarizing clinical evaluation and diagnosis flowchart for TVE (see text for details and references). CIED, cardiac implantable electronic device; CoNS, coagulase-negative staphylococci; HIV, human immunodeficiency virus; IVDU, intravenous drug user; GP, general practitioner.

TVE is heterogeneous and is largely determined by the severity of TR. Although a large proportion of patients have respiratory symptoms resulting from pulmonary emboli, pneumonia, and pulmonary abscess formation, the majority of them can be managed medically with good outcome (7). If left untreated, TVE with severe TR can lead to right ventricular dysfunction, heart failure, pulmonary hypertension, and atrial fibrillation. In the case of chordae rupture severe right heart haemodynamic dysfunction can rapidly occur. The mortality rate in TVE due to CIED is approximately $14.7 \%$ at 30 days to $23.2 \%$ at 1 year (8) (Figure 1).

This review summarizes the currently available evidences on TVE including surgical indications, interventions and technical considerations.

We present the following article in accordance with the Narrative Review reporting checklist (available at http:// dx.doi.org/10.21037/atm-20-4685). 


\section{Methods}

A literature search of PubMed, EBSCO, Embase, Web of Science and Cochrane database of systematic reviews was performed, using the following keywords and MESH terms in various combinations: "endocarditis", "infective", "tricuspid valve", "tricuspid valve repair", "tricuspid valve replacement", "tricuspid valvectomy", "cardiac implantable device", "pacemaker infection".

\section{The surgeon and the tricuspid anatomy}

Accurate knowledge of the anatomy of the TV and the right ventricle $(\mathrm{RV})$ is important for the surgeon during the repair or replacement procedure. The TV and subvalvular apparatus include valve leaflets, the annulus, papillary muscles and chordae tendinae.

\section{TV leaflets}

The valve has commonly 3 leaflets of unequal size but in some cases is possible to identify 2 (bicuspid) or more leaflets $(9,10)$. The three leaflets are named according to their anatomic position as the septal, anterior-superior, and inferior leaflets (11). The anterior leaflet is generally more developed in length and width with radial direction, larger area and the greatest motion. Conversely, the posterior leaflet can sometimes be characterized by multiple scallops. The septal leaflet is the shortest with minimal mobility and inserts into the tricuspid annulus directly above the interventricular septum (12). The commissure between the septal and posterior leaflets is typically located near the ostium of the coronary sinus in the right atrium (RA). The anteroseptal commissure, which includes the septal and anterior leaflets, is the longest compared to the posterior one and located near the non-coronary sinus of Valsalva of the aortic root. The length of the commissure is due to the fact that the anterior and septal leaflets have the largest circumference.

\section{TV annulus}

Despite valvular annulus is normally by a distinct fibrous structure, anatomical studies on healthy cadavers suggested that the term is improper for the TV annulus. In fact, the presence of fibrous tissue is very scarce and primarily localized in the septal segment of the annulus (13). The normal tricuspid annulus has a D-shaped with 2 distinct segments: a larger C-shaped segment which corresponds to the free wall of RA and the RV, and a shorter segment that appears straight and corresponds to the septal leaflet and the ventricular septum. The structure of the TV annulus makes it more fragile to traction during surgical manipulation. It is constituted by multiple muscular strands measuring approximately 2 to $4 \mathrm{~mm}$ in diameter, extending from the free wall of the RV and the septal wall. This peculiar morphostructure organized in muscle bands can offer support to the non-fibrous RA-RV junction which is therefore a weak part of the right heart. From histological point of view, it is constituted by very little fibrous tissue along with endocardium (13).

\section{Subvalvular apparatus}

The anatomy of tensor apparatus of TV, which comprehends the papillary muscles and chordae tendinae (14), play a pivotal role in TV repair even more when a cryopreserved homografts were used (15-18). The subvalvular apparatus of the TV is formed by the anterior and posterior papillary muscles and by a third papillary muscle whose existence is variable. Chordae tendinae of the TV consist of fibrous cords with different lengths that connect the papillary muscles to the TV leaflets.

The anterior papillary muscle is generally the most developed and gives rise the chordae tendinae which are destined to the anterior and posterior leaflet. The moderating band (trabecula septomarginalis) can be attached to this papillary muscle. The posterior papillary muscle often has two or three heads and the chordae tendinae intended for the posterior and septal leaflets derive from this papillary muscle. As for the septal papillary muscle, it is often variable, being small or multiple or even absent up to $20 \%$ of normal subjects. In the absence of the papillary muscle, the septal chordae tendinae can derive directly from the septum heading towards the anterior and septal leaflets. Therefore, the septal and anterior leaflets of the TV are connected to the interventricular septum and the anterior and posterior leaflets may depend on a large anterior papillary muscle located along the antero-lateral RV wall.

Normally, the chordae vary in number from 17 to 36 with an average of 25 and are differentiated in five types according to their morphology and site of attachment to the leaflet: fan-shaped, rough zone, basal, free edge, and deep chordae (18). The true chordae typically arise from the apical third of the papillary muscle but can also derive 
from the ventricular walls, and in this case are attached to the septal leaflet $(18,19)$. Chordae tendinae are constituted approximately by $80 \%$ collagen, whereas the remaining $20 \%$ is made of elastin and endothelial cells. Accessory chordae tendinae can origin from the free wall of the $\mathrm{RV}$ and the trabecula septomarginalis. The subvalvular apparatus may be constituted by false chordae that are inserted in various parts and connect the two papillary muscles, a papillary muscle with the ventricular wall, or two points of the ventricular wall (18).

\section{Biomechanics}

From the biomechanical and ultrastructural points of view difference exists between the chordae tendinae of the tricuspid and the mitral valve. In the non-pathological human TV, the chordae tendinae consist of substantially straight bundles of collagen which are organized in a network of fibrils. This particular morphostructure provides less extensibility to the chordae when compared to the normal mitral valve's ones of comparable size (20). The mechanical behavior of the chordae tendinae can explain the marked tethering occurring with the dilation of the RV or displacement of the papillary muscles. Mee et al. showed that excessive tethering in patients with Ebstein disease could be corrected with a papillary muscle reapproximation (21).

\section{Surgical practical considerations}

A comprehensive anatomical knowledge of both the components of the TV and the adjacent structures is crucial in approaching TV surgery (Figure 2). When performing a TV repair operation, it should be considered that the coaptation of the TV is normally at or just below the annulus level, with a coaptation length of 5 to $10 \mathrm{~mm}$ (18). Conversely, an excess of coaptation length should be taken into account when using a homograft to replace or repair the TV (15-17). Importantly, due to the fact that the length of the chordae is fixed, the displacement of the RV septum or the side wall may affect the coaptation of the tricuspid leaflet. Therefore, wide coaptation length may function as a "reserve" when performing restrictive annuloplasty (15-17). Finally, the network of chordae can interfere with catheters and devices used during the interventional cardiological procedures, with additional challenge in transcatheter approaches.

\section{Etiology, pathophysiology and treatment}

TVE is characterized predominantly by regurgitation. During the 20th century, the disease was common in younger and middle-aged adult patients with underlying rheumatic heart disease. The principal pathogen responsible for the infection was oral streptococci in high-income countries $(22,23)$.

In the 21 st century, with the growing development of antibiotic treatment, the risk profile of patients and the pathogen responsible for the infection changed. Patient demography includes IVDU, CHD and immunosuppression which became the main risk factors in the younger and middle-aged population (4,6,23-29). On the other hand, in older patients with increasing comorbidities, TVE is more associated to hemodialysis and permanent venous catheters. In fact, in the 21 st century, with the expanding use of CIEDs a $25 \%$ increased incidence of iatrogenic infective endocarditis (IE) was registered in the cardiology practice $(8,30,31)$. At the same time, staphylococci strains exceeded oral streptococci as the most frequent causative pathogen $(32,33)$. Both pathogens can lead to leaflet damage and extensive infection. Colonisation of coagulase-negative staphylococci (CoNS) (e.g., Staphylococcus epidermidis, Staphylococcus lugdunensis, and Staphylococcus capitis) can lead to destruction of both valvular and subvalvular apparatus with nefarious evolution (34). Annular dilatation may also develop over time, leading to further progression of TR.

Cardiac device infection is disproportionately growing in the United States compared to increasing implantation rates. CIEDs include permanent pacemakers, implantable cardioverter defibrillators, and cardiac resynchronization therapy devices (30), with an incidence of cardiac device infection after first implantation ranging from 1 to 10 per 1,000 device/years. The rate of infection is variable considering the different types of device and it is approximately 1 per 1,000 device years for pacemakers and 8 to 9 per 1,000 device-years for complex devices) (35-37). The concern associated with this complication is that patients with a CIEDs have an increase in short and longterm morbidity and mortality as well as an increasing cost of management which is estimated at over $\$ 15,000$ per patient $(38,39)$.

CIEDs infection may involve the generator pocket, device leads with an extension to endocardial tissue surfaces. The infection may be located on valvular and/or nonvalvular structures. Generally, in pocket infections cellulitis, 


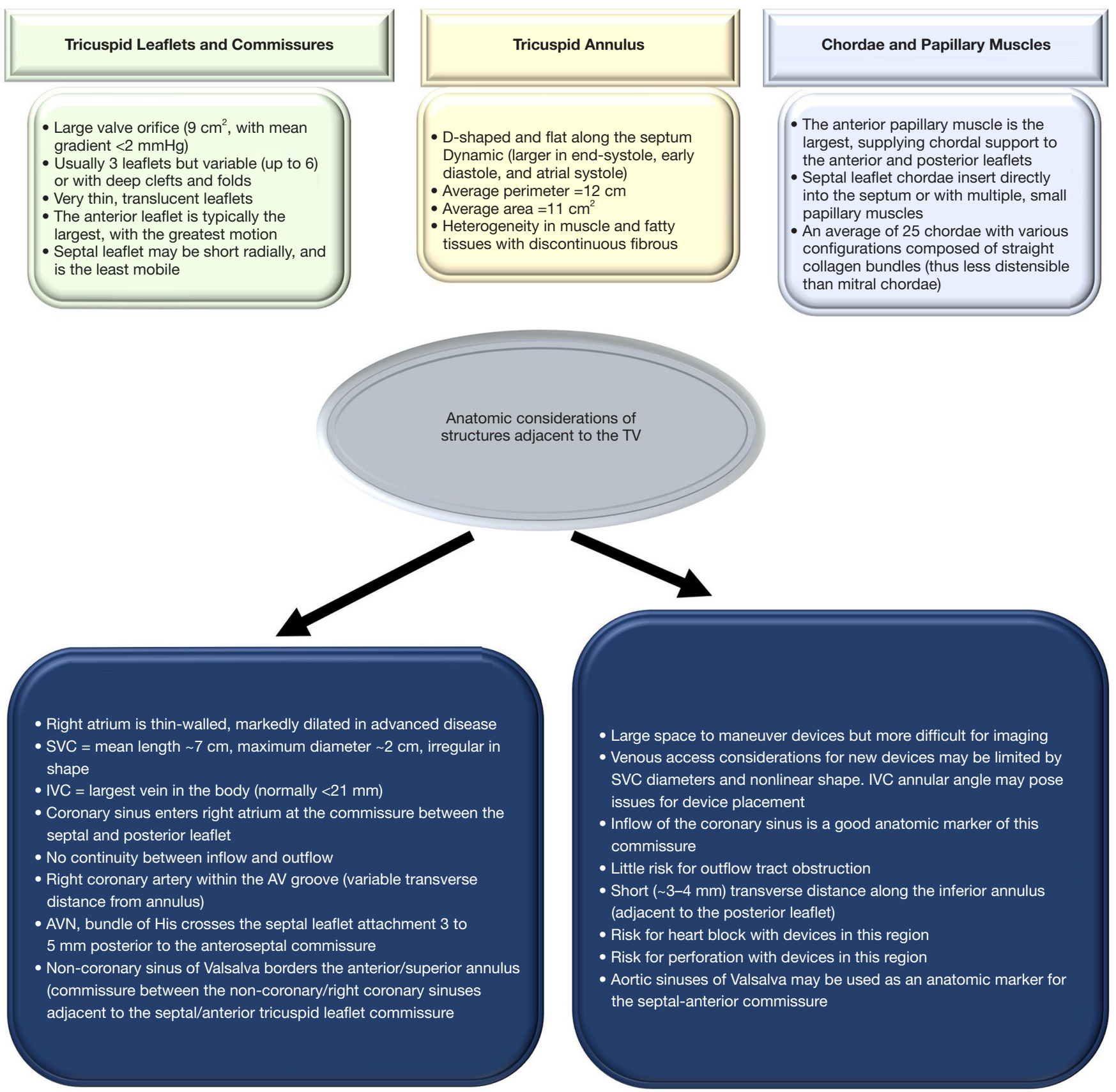

Figure 2 Surgical anatomical consideration in TV surgery including TV components (top), and (bottom) anatomical structures located in proximity of the TV (left arrow) and subvalvular apparatus (right arrow). TV, tricuspid valve; SVC, superior vena cava; IVC, inferior vena cava; AV, atrioventricular; AVN, atrioventricular node.

erythema, up to erosion of the device on the skin above the pocket can be seen. Patients who have an infection involving CIED leads or the endocardial surface (CIEDIE) present systemic symptoms as fevers and rigors related to septicaemia. The pathogen implicated are Staphylococci strains (in particular CoNS) that represent $60-80 \%$ of cases (40). Surgical management of this infection is an expanding field. Risks associated to the procedure include the development of a postoperative hematoma [odds ratio (OR) 8.46; 95\% confidence interval (CI), 4.01-17.86], 


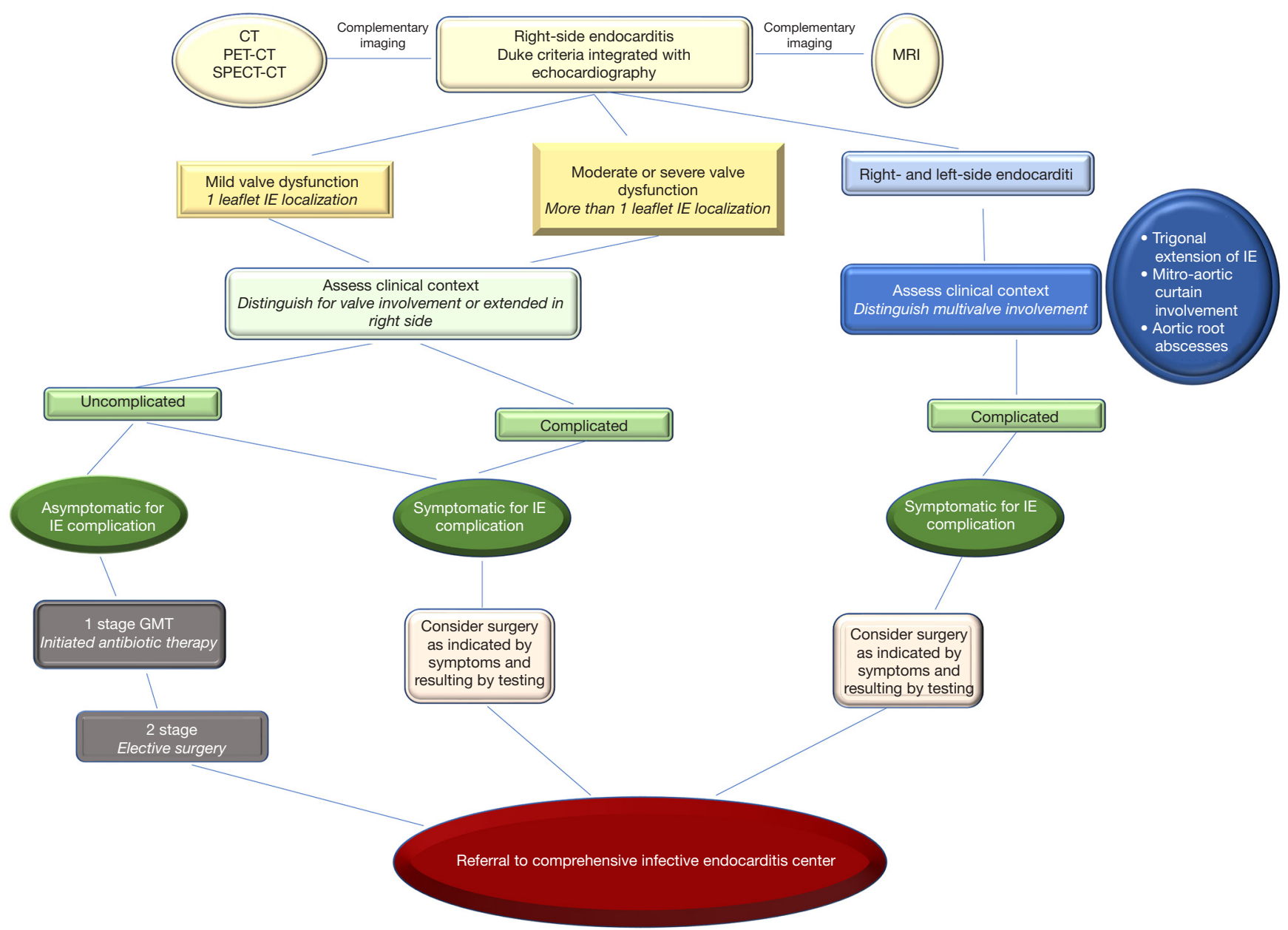

Figure 3 Clinical algorithm for the management of TVE. IE, infective endocarditis; CT, computed tomography; PET, positron emission tomography; GMT, guide medical therapy; MRI, magnetic resonance imaging; SPECT, single-photon emission computed tomography.

reoperation for lead displacement with prolonged operation times. Surgical extraction and tricuspid reconstruction is sometimes necessary. Patients who require a revision procedure are exposed to a 2 - to 5 -fold higher risk of reinfection. Use of antibiotic prophylaxis has been shown to protect against Clostridioides difficile infection (CDI) in both randomised controlled trials (RCTs) and observational studies (41).

The approach to TVE requires consideration of several aspects including the causative pathogen, the premorbid conditions, the clinical conditions and potential deterioration and the extent of the infection and the decision-making in terms of treatment is guided by those parameters (Figure 3).

Patients with mild-to-moderate TR due to small vegetation may remain asymptomatic and without clinical deterioration or often have respiratory symptoms resulting from pulmonary emboli, pneumonia, and pulmonary abscess formation. However, TR imposes a volume load on the RV, which, if sustained over time, results in ventricular dilatation, neurohumoral activation and heart failure. In addition, elevation in the mean right atrial pressure leads to right atrial enlargement and atrial fibrillation (42-45).

The objective of surgery is to restore a valve competency. There are two main options for surgical correction of severe TR: TV replacement (TVR) or repair with annuloplasty (TVP) (46).

Tricuspid-valve replacement can be achieved with the use of either conventional mechanical or stented xenograft prosthesis. However, there are several disadvantages 
associated to TVR. including the need for lifelong anticoagulation and the higher risk of thromboembolism with the use of mechanical valves. Conversely, the use of conventional xenograft valves has the drawbacks of structural valve degeneration with failure and the risk of prosthetic-valve endocarditis due to relapse of infection, especially in IVDUs.

The goals of TVP are to obtain complete removal of infectious vegetation along with the valvular and subvalvular apparatus, to restore a proper line of coaptation on both leaflets, to reintegrate the continuity between leaflet and annulus of the TV, to correct annular dilatation, and to preserve (or repair, if necessary) the subvalvular apparatus (46-48).

\section{Clinical evidence}

There is no randomized study investigating the ideal substitute in patients with severe TR due to TVE. However, evidence from observational series strongly suggests that surgical intervention is beneficial in IVDU and in infected CIEDs. A study from Cleveland Clinic (49) evaluated the impact of surgery on long-term outcomes of isolated rightsided and left-sided IE with IVDU and CIEDs patients with chronic vascular access were the majority of the population. Patient were followed-up for a mean of 5.2 years. Surgery for TVE was used for 127 out of 134 patients of which 90 patients had valve repair/reconstruction while 27 received a prosthetic valve replacement. Suture annuloplasty or combination of implant of artificial chords and an annuloplasty ring were used for repair/reconstructions the TV. The patients undergoing repair/reconstruction had a significantly better 5 -year survival rate than those managed with a replacement $(60 \%$ vs. $20 \%, \mathrm{P}=0.03)$. Survival varied according to predisposing conditions. Five-year survival was $59 \%$ in patients with cardiac implantable devices and $60 \%$ in IVDU. At 9-year follow-up mortality in CIEDs group was higher than IVDU (30\% vs. $\left.60 \% \mathrm{P}_{\text {logrank }}=0.009\right)$. Survival was lower for patients with combined right- and left-sided IE than for those with isolated right-sided IE $(\mathrm{P}=0.03)$. The risk of infection relapse was higher in IVDU. Five-year freedom from reinfection was $87 \%$ with a rate of $76 \%$ in IVDU and $93 \%$ in the rest of the population. Incidence of reinfection did not differ significantly between those who had tricuspid repair/reconstruction compared to those were managed with replacement.

In another report from the Harvard group $(25,50) 436$ patients with IE were studied, 78 of these were IVDUs.
Right-side valve involvement was observed in 38 patients and 20 were IVDU. The largest number of patients $(n=27)$ received a repair/reconstructions and a minimal percentage received replacement with a prosthesis or a cryopreserved homograft (25). Interestingly, after adjustments for baseline characteristics and propensity-score match, use of a homograft did not significantly affect early death (OR 1.61; 95\% CI, 0.73-3.40, $\mathrm{P}=0.23$ ), overall death [hazard ratio (HR) $1.10 ; 95 \% \mathrm{CI}, 0.62-1.94, \mathrm{P}=0.75$ ], or reinfection (HR 1.04; 95\% CI, 0.49-2.18, $\mathrm{P}=0.93$ ) (45). Overall, 10 year survival rates were $69.5 \% \pm 8.3 \%$ in IVDUs, and $68.7 \% \pm 3.9 \%$ in non-IVDUs, respectively $(\mathrm{P}=0.39)$. When adjusted by propensity score, IVDUs tended to have lower risk of early mortality (HR 0.32; 95\% CI, 0.08-1.36; $\mathrm{P}=0.13$ ) but with higher risk of late mortality (HR 2.07; 95\% CI, 0.78-5.48; $\mathrm{P}=0.14$ ) compared with non-IVDUs; however, these trends were not statistically significant (25). In a recent metanalysis including 12 unmatched retrospective observational studies and 1,165 patients with a median follow-up of 3.8 years, TVP and TVR had similar short and long-term survival. TVP was associated with greater freedom from recurrent IE [relative risk (RR) 0.17 , 95\% CI, 0.05-0.57, $\mathrm{P}=0.004]$ and reoperation (RR 0.26, $95 \% \mathrm{CI}, 0.07-0.92, \mathrm{P}=0.04)$ but a trend toward greater risk of moderate to severe TR (RR 4.14, 95\% CI, 0.80-21.34, $\mathrm{P}=0.09$ ). Importantly, valve repair had lower risk for permanent pacemaker implantation (RR 0.20, 95\% CI, $0.11-0.35, \mathrm{P}<0.001)(51)$.

There is no randomized evidence comparing surgery for TVE with medical treatment. Despite observational studies suggest a benefit of TV surgery (52), medical therapy alone can be effective for right-sided IE even when large vegetations were present (53). Aksoy et al. reported 426 patients with a left-side endocarditis (LSE $n=333$ ) and a right-side endocarditis (RSE $\mathrm{n}=96$ ) who received medical treatment or surgery (52). Using individual propensity scores, 51 patients who received medical and surgical treatment were matched with 51 patients who had medical treatment only. The analysis of patients characteristics and mortality were evaluated during a 5-year follow-up period. Regression analysis of the matched cohorts showed that surgery was associated with decreased mortality (HR 0.27; 95\% CI, 0.13-0.55). Presence of intravascular catheters at diagnosis was independently associated with increased mortality (HR 2.65; 95\% CI, 1.31-5.33) (52).

Otome et al. reported a retrospective analysis of consecutive 49 IVDUs with native TVE and compared tricuspid-valve surgery with medical treatment. No 
difference in mortality was shown in relation to vegetation size in medically treated patients, however a bacteraemia score $>4$ was associated with a mortality of $24 \%(\mathrm{P}=0.026)(53)$.

A prospective cohort analysis from the International Collaboration on Endocarditis-Prospective Cohort Study (ICE-PCS) conducted in 61 centers in 28 countries reported 177 patients with CEIDs who developed IE (8). Vegetations of tricuspid-valve occurred in $24.3 \%$ of the patients. There was a significant survival benefit for patients undergoing surgery $v s$. medical therapy [1-year survival, $19.9 \%$ vs. 38,2.5\%; HR for death 0.42 (95\% CI, 0.22-0.82)]. Staphylococcus and coagulase negative staphylococcal strains had significantly higher mortality rate $95 \%$ CI, $28.0-42.5 \%$ and $24.9-39.0 \%$, respectively).

Mann et al. reported a significant involvement of the TV in 428 IE [native native valve endocarditis (NVE) $n=283$, prosthetic prosthetic valve endocarditis (PVE) $n=199$ ] retrospectively studied. A multivalvular involvement was shown in $19.1 \%$ of the patients, with $35.5 \%$ incidence of TVE (NVE =85, PVE =67). No significant difference in long-term survival was shown between NVE and PVE. Patients with IE caused by Staphylococcus aureus had higher 1 -year mortality (28\% vs. $18 \%$; $\mathrm{P}=0.02)$ compared with non-S. aureus etiologies (54).

In a recent retrospective study from Australia, TVE had a lower incidence (38\%) than left-sided IE (53\%) in IVDUs. There was no significant survival benefit in patients with heart failure and large vegetation $(>1 \mathrm{~cm})$ undergone valve surgery (55).

\section{Surgery: indications and options}

Patients with severe symptomatic TR or RV dysfunction should be offered surgery. Generally, these patients have vegetation size greater than $20 \mathrm{~mm}$, worsening heart failure, and persistent infection. The increased pulmonary artery pressure (PAP) may determine morphologic changes with tricuspid annular and early right atrial and ventricular dilation. Patients with TVE with extension of the infection through the aortic non-coronary sinus or mitral valve (trigonal lesion), should be considered for surgery even without right ventricular dysfunction or dilatation, if pulmonary hypertension establishes $(42,56)$.

Asymptomatic patients with mild to moderate TR, vegetations $<1 \mathrm{~cm}$, and no evidence of $\mathrm{RV}$ dysfunction or dilatation should receive antibiotic treatment and observed for clinical deterioration until symptoms or severe TR occurs (56).

Tricuspid-valve repair (TVP) is preferred to TVR procedure $(48,49,54,56)$. Recently, surgeons from Kentucky (47) reported that TVR can be considered in young patients, bilateral emboli, and in infections sustained by methicillin-sensitive S. aureus (MSSA). For TVR, the use biological derivates over mechanical prosthesis is generally preferred for the lower risk of thromboembolic complication $(16,25,26,49,54,56)$.

Tricuspid-valve repair is recommended in older patients with clinically significant comorbidities, such as advanced respiratory, hepatic, or renal dysfunction, or those with recent pulmonary events or CIEDs (8). In first-time IE, TVP is preferred in IVDUs, while TVR is preferable in cases of reoperation of patients with high recurrence rate and in patients who require a reoperation for a PVE and extended infection.

Another potential but controversial option regards surgical valvectomy as a temporary bridge therapy in attendance of staged TVR. The choice between valvectomy and valve replacement is also debated. In the presence of extensive lesions involving more than one scallop or more than one leaflet and in young patients, it is preferable to perform a TVR. In patients with persistent sepsis, abscess formation, ongoing drug use, and poor compliance to rehabilitation programs valvectomy is recommended (56). Despite pulmonary artery hypertension is a contraindication to valvectomy, patients with high pulmonary pressure can well tolerate valvectomy. This might be due to several factors: (I) large reserve of young patients, (II) a possible good physiological compensation secondary to longstanding preoperative heart failure and (III) a perioperative improvement of PAPs secondary to the continued treatment of septic pulmonary emboli with effective targeted antibiotic therapy (57).

The mortality rate after valvectomy varies across the literature compared with TVR. Several reports have shown a higher mortality in patients who received tricuspid valvectomy, but this discrepancy may be related to the type of pathogen involved, the advancements of perioperative and critical care, and more effective targeted antibiotic treatment over the course of the years (57-61). Protos et al. diverge from these conclusions reporting better survival (47).

In IVDUs, the concern regarding the replacement of the TV is due to the fact that abuse relapse may result in infection of the prosthetic valve. Readmission rate at 1 year after discharge was less common in valvectomy. Factors as the pathogen sustaining prosthetic reinfection, antibiotic 
resistance and emergency surgery are important in relapses after TVR. Conversely, in patients who received a tricuspid valvectomy as a bridge procedure hospital admission to perform valve replacement surgery is electively planned after 6 weeks of targeted antibiotic therapy, reducing the risk of the procedure. A recent meta-analysis has shown no differences in major cardiovascular events, infection recurrence and postoperative right heart failure when comparing valvectomy to TVR. Authors concluded that valvectomy could represent an acceptable initial bridging therapy for TVE giving time to identify candidates for staged valve replacement (48). This also has significant social and economic implications considering the costs for valve prosthesis clinical follow-up in non-compliant patients and the higher risk of emergent valve replacement in cases of reinfection $v s$. an elective valve implant in a staged procedure (62-64).

\section{Surgery: technical considerations}

In patients with isolated infection of the leaflet scallop of TV due to the IVDU, limited resection of infected leaflet is performed with the removal of the minimum number possible of adjacent chordae (15). The remaining segments of the TV leaflet are approximated. The annulus is reconstructed and supported with a prosthetic ring (17) although some surgeons prefer a DeVega annuloplasty $(47,49,54)$, as avoids the use synthetic material. Limited resection and the use of artificial chordal replacement (with Gore-Tex expanded polytetrafluoroethylene sutures) and annuloplasty reinforcement may also be appropriate in cases of TVE with extended infection to subvalvular apparatus tissue. In patients with complex TVR a cryopreserved homograft valve replacement may be a suitable alternative to the use of conventional mechanical or stented xenograft prosthesis, especially when valve repair involves more leaflets or scallops.

Extensive PVE or progression of primary infectious from aortic non coronary sinus or/and mitral valve through the trigone (trigonal abscess) can require demolitive surgery and in these cases the use of cryopreserved homograft is recommended (15-17). If the vegetation is located on antero-septal commissure or between anterior and posterior leaflet with no further involvement of leaflets scallops, reconstruction after excision of the infected segment can be performed using a partial homograft. Conversely, aortictricuspid extension, circumferential aortic annular abscess or the development of intracardiac fistulas, requires complete debridement of the infected tissue and reconstruction with full homografts. In some instances, the use of cryopreserved mitral homograft in tricuspid position has been described $(65,66)$. The use of homografts has also been found effective by the Harvard group $(25,50)$. However, individual and institutional experience is crucial in determining the likelihood of success of a homograft procedure. Highvolume centers have the highest proportion of patients with complex IE and the lowest mortality rates.

From the technical standpoints, isolated tricuspid operations could be performed on beating heart venting and unloading the heart cavities. However, homografts procedures or more complex surgical interventions for extensive endocarditis might require to open the interventricular septum, RV or inter atrial septum and demands for full cardiopulmonary bypass.

The treatment of right sided endocarditis related to CIED is an emergent field $(8,49,54)$ and recent reports are suggesting as delay in decision-making and lack of experience in this filed may result in intraprocedural and postoperative complications (67). The aim of surgery is to remove the infection, restore competence of the TV and reduce the risk of bacterial pulmonary embolism during removal of the infection. The extent of the infection guides treatment and if only the leads are involved, simple extraction of the infected material could be performed percutaneously $(8,49)$. However, these procedures should be performed at the presence of a cardiac surgeon as the risk of RV rupture, especially when removing multiple catheters or long-term implants, is high and requires immediate sternotomy and surgical repair. Vegetations or damage of the TV demands for concomitant valve surgery including vegetectomy, leaflet repair with pericardial patch, TVP or TVR. From current reports analyzing the worrisome epidemiology of the problem and the causative etiology, it appears that the two tenets for an adequate management strategy of CIEDs-related TVE are the creation of dedicated endocarditis team composed by surgeons and cardiologist to avoid delay in diagnosis and treatment, and a stricter antibiotic prophylaxis policy directed to protect high-risk patients and to contain the increasing multidrug resistance (68). Another growingly important subset of patients at risk for TVE is represented by patients with end-stage kidney disease requiring vascular access and CIEDs. In these situations, riskreduction strategy foresees the creation of arteriovenous fistula on the contralateral upper limb for a CIED and avoidance of central vein catheter. The increasing 
introduction of miniaturized CIEDs and even leadless pacemaker/implantable is an important perspective for patients with rapid progression of chronic kidney disease (69).

\section{Conclusions}

TVE is a surgical expanding concern with increasing rates and mortality burden. The progressively widespread use of CIEDs is adding to the more commonly known IV drug abuse in the list of causes. Surgical treatment includes valve repair, replacement or the staged procedure of valvectomy as bridge to replacement. However, the lack of specific randomized evidences and the non-unanimous results from the currently available observational evidences impede to reach a definitive conclusion regarding the best management strategy.

The recent advancement in antibiotic therapy and critical care add to the armamentarium of the surgeon in TVE, but the changing etiology, the antibiotic resistance and the raise of iatrogenic causes of IE demands further research efforts for the identification of the best management strategy and novel therapeutic approaches.

\section{Acknowledgments}

Funding: None.

\section{Footnote}

Provenance and Peer Review: This article was commissioned by the Guest Editors (Drs. Francesco Nappi, Christos Mihos, and Cristiano Spadaccio) for the series "Infective Endocarditis in the 21st Century" published in Annals of Translational Medicine. The article was sent for external peer review organized by the Guest Editors and the editorial office.

Reporting Checklist: The authors have completed the Narrative Review reporting checklist. Available at http:// dx.doi.org/10.21037/atm-20-4685

Conflicts of Interest: All authors have completed the ICMJE uniform disclosure form (available at http:// dx.doi.org/10.21037/atm-20-4685). The series "Infective Endocarditis in the 21st Century" was commissioned by the editorial office without any funding or sponsorship. FN serves as an unpaid editorial board member of Annals of Translational Medicine from Feb 2019 to Jan 2021. FN, CS and CM served as the unpaid Guest Editors of the series. The other authors have no other conflicts of interest to declare.

Ethical Statement: The authors are accountable for all aspects of the work in ensuring that questions related to the accuracy or integrity of any part of the work are appropriately investigated and resolved.

Open Access Statement: This is an Open Access article distributed in accordance with the Creative Commons Attribution-NonCommercial-NoDerivs 4.0 International License (CC BY-NC-ND 4.0), which permits the noncommercial replication and distribution of the article with the strict proviso that no changes or edits are made and the original work is properly cited (including links to both the formal publication through the relevant DOI and the license). See: https://creativecommons.org/licenses/by-nc-nd/4.0/.

\section{References}

1. Cahill TJ, Prendergast BD. Infective endocarditis. Lancet 2016;387:882-93.

2. Cahill TJ, Baddour LM, Habib G, et al. Challenges in Infective Endocarditis. J Am Coll Cardiol 2017;69:325-44.

3. Allegranzi B, Bagheri Nejad S, Combescure C, et al. Burden of endemic health-care-associated infection in developing countries: systematic review and meta-analysis. Lancet 2011;377:228-41.

4. Slipczuk L, Codolosa JN, Davila CD. Infective endocarditis epidemiology over five decades: a systematic review. PLoS One 2013;8:82665.

5. Dayer MJ, Jones S, Prendergast B, et al. Incidence of infective endocarditis in England, 2000-13: a secular trend, interrupted time-series analysis. Lancet 2015;385:1219-28.

6. Prendergast $\mathrm{BD}$. The changing face of infective endocarditis. Heart 2006;92:879-85.

7. Martín-Dávila P, Navas E, Fortún J. Analysis of mortality and risk factors associated with native valve endocarditis in drug users: the importance of vegetation size. Am Heart J 2005;150:1099-106.

8. Athan E, Chu VH, Tattevin P. Clinical characteristics and outcome of infective endocarditis involving implantable cardiac devices. JAMA 2012;307:1727-35.

9. Xanthos T, Dalivigkas I, Ekmektzoglou KA. Anatomic variations of the cardiac valves and papillary muscles of the 
right heart. Ital J Anat Embryol 2011;116:111-26.

10. Hahn RT. State-of-the-Art Review of Echocardiographic Imaging in the Evaluation and Treatment of Functional Tricuspid Regurgitation. Circ Cardiovasc Imaging 2016;9:e005332.

11. Martinez RM, O'Leary PW, Anderson RH. Anatomy and echocardiography of the normal and abnormal tricuspid valve. Cardiol Young 2006;16 Suppl 3:4-11.

12. Rogers JH, Bolling SF. The tricuspid valve: current perspective and evolving management of tricuspid regurgitation. Circulation 2009;119:2718-25.

13. Messer S, Moseley E, Marinescu M, et al. Histologic analysis of the right atrioventricular junction in the adult human heart. J Heart Valve Dis 2012;21:368-73.

14. Tretter JT, Sarwark AE, Anderson RH, et al. Assessment of the anatomical variation to be found in the normal tricuspid valve. Clin Anat 2016;29:399-407.

15. Nappi F, Nenna A, Petitti T, et al. Long-term outcome of cryopreserved allograft for aortic valve replacement. J Thorac Cardiovasc Surg 2018;156:1357-1365.e6.

16. Nappi F, Spadaccio C, Acar C. Use of allogeneic tissue to treat infective valvular disease: Has everything been said? J Thorac Cardiovasc Surg 2017;153:824-8.

17. Olivito S, Lalande S, Nappi F. Structural deterioration of the cryopreserved mitral homograft valve. J Thorac Cardiovasc Surg 2012;144:313-20.

18. Nappi F, Singh SSA, Lusini M, et al. The use of allogenic and autologous tissue to treat aortic valve endocarditis. Ann Transl Med 2019;7:491.

19. Karas S, Elkins RC. Mechanism of function of the mitral valve leaflets, chordae tendineae and left ventricular papillary muscles in dogs. Circ Res 1970;26:689-96.

20. Lim KO. Mechanical properties and ultrastructure of normal human tricuspid valve chordae tendineae. Jpn J Physiol 1980;30:455-64.

21. Mee RB. Congenital heart surgery. Curr Opin Cardiol 1992;7:249-58.

22. Seckeler MD, Hoke TR. The worldwide epidemiology of acute rheumatic fever and rheumatic heart disease. Clin Epidemiol 2011;3:67-84.

23. Yew HS, Murdoch DR. Global trends in infective endocarditis epidemiology. Curr Infect Dis Rep 2012;14:367-72.

24. Correa de Sa DD, Tleyjeh IM, Anavekar NS, et al. Epidemiological trends of infective endocarditis: a population-based study in Olmsted County, Minnesota. Mayo Clin Proc 2010;85:422-6.

25. Kim JB, Ejiofor JI, Yammine M. Surgical outcomes of infective endocarditis among intravenous drug users. J Thorac Cardiovasc Surg 2016;152:832-41.

26. Day MD, Gauvreau K, Shulman S, et al. Characteristics of children hospitalized with infective endocarditis. Circulation 2009;119:865-70.

27. Rushani D, Kaufman JS, Ionescu-Ittu R. Infective endocarditis in children with congenital heart disease : cumulative incidence and predictors. Circulation 2013;128:1412-9.

28. Morris CD, Reller MD, Menashe VD. Thirty-year incidence of infective endocarditis after surgery for congenital heart defect. JAMA 1998;279:599-603.

29. Valente AM, Jain R, Scheurer M. Frequency of infective endocarditis among infants and children with Staphylococcus aureus bacteremia. Pediatrics 2005;115:15-9.

30. Voigt A, Shalaby A, Saba S. Rising rates of cardiac rhythm management device infections in the United States: 1996 through 2003. J Am Coll Cardiol 2006;48:590-1.

31. Greenspon AJ, Patel JD, Lau E, et al. 16-year trends in the infection burden for pacemakers and implantable cardioverter-defibrillators in the United States 1993 to 2008. J Am Coll Cardiol 2011;58:1001-6.

32. Fowler VG, Miro JM, Hoen B, et al. Staphylococcus aureus endocarditis: a consequence of medical progress. JAMA 2005;293:3012-21.

33. Murdoch DR, Corey GR, Hoen B, et al. Clinical presentation, etiology, and outcome of infective endocarditis in the 21st century: the International Collaboration on Endocarditis-Prospective Cohort Study. Arch Intern Med 2009;169:463-73.

34. Becker K, Heilmann C, Peters G. Coagulase-negative staphylococci. Clin Microbiol Rev 2014;27:870-926.

35. Uslan DZ, Sohail MR, St Sauver JL, et al. Permanent pacemaker and implantable cardioverter defibrillator infection: a population-based study. Arch Intern Med 2007;167:669-75.

36. Johansen JB, Jørgensen OD, Møller M. Infection after pacemaker implantation: infection rates and risk factors associated with infection in a population-based cohort study of 46299 consecutive patients. Eur Heart J 2011;32:991-8.

37. Landolina M, Gasparini M, Lunati M. Long-term complications related to biventricular defibrillator implantation: rate of surgical revisions and impact on survival : insights from the Italian Clinical Service Database. Circulation 2011;123:2526-35.

38. Rizwan Sohail M, Henrikson CA, Jo Braid-Forbes M, 
et al. Increased long-term mortality in patients with cardiovascular implantable electronic device infections. Pacing Clin Electrophysiol 2015;38:231-9.

39. Sohail MR, Henrikson CA, Braid-Forbes MJ, et al. Mortality and cost associated with cardiovascular implantable electronic device infections. Arch Intern Med 2011;171:1821-8.

40. Bongiorni MG, Tascini C, Tagliaferri E, et al. Microbiology of cardiac implantable electronic device infections. Europace 2012;14:1334-9.

41. Da Costa A, Kirkorian G, Cucherat M, et al. Antibiotic prophylaxis for permanent pacemaker implantation: a meta-analysis. Circulation 1998;97:1796-801.

42. Nishimura RA, Otto CM, Bonow RO, et al. 2017 AHA/ ACC Focused Update of the 2014 AHA/ACC Guideline for the Management of Patients With Valvular Heart Disease: A Report of the American College of Cardiology/ American Heart Association Task Force on Clinical Practice Guidelines. J Am Coll Cardiol 2017;70:252-89.

43. Habib G, Lancellotti P, Antunes MJ, et al. 2015 ESC Guidelines for the management of infective endocarditis: The Task Force for the Management of Infective Endocarditis of the European Society of Cardiology (ESC). Endorsed by: European Association for Cardio-Thoracic Surgery (EACTS), the European Association of Nuclear Medicine (EANM). Eur Heart J 2015;36:3075-128.

44. Habib G, Derumeaux G, Avierinos JF, et al. Value and limitations of the Duke criteria for the diagnosis of infective endocarditis. J Am Coll Cardiol 1999;33:2023-9.

45. Baddour LM, Wilson WR, Bayer AS, et al. Infective Endocarditis in Adults: Diagnosis, Antimicrobial Therapy, and Management of Complications: A Scientific Statement for Healthcare Professionals From the American Heart Association. Circulation 2015;132:1435-86.

46. Iung B, Doco-Lecompte T, Chocron S, et al. Cardiac surgery during the acute phase of infective endocarditis: discrepancies between European Society of Cardiology guidelines and practices. Eur Heart J 2016;37:840-8.

47. Protos AN, Trivedi JR, Whited WM, et al. Valvectomy Versus Replacement for the Surgical Treatment of Tricuspid Endocarditis. Ann Thorac Surg 2018;106:664-9.

48. Luc JGY, Choi JH, Kodia K, et al. Valvectomy versus replacement for the surgical treatment of infective tricuspid valve endocarditis: a systematic review and metaanalysis. Ann Cardiothorac Surg 2019;8:610-20.

49. Witten JC, Hussain ST, Shrestha NK. Surgical treatment of right-sided infective endocarditis. J Thorac Cardiovasc Surg 2019;157:1418-27.
50. Kim JB, Ejiofor JI, Yammine M, et al. Are homografts superior to conventional prosthetic valves in the setting of infective endocarditis involving the aortic valve ? J Thorac Cardiovasc Surg 2016;151:1239-46.

51. Yanagawa B, Elbatarny M, Verma S, et al. Surgical Management of Tricuspid Valve Infective Endocarditis: A Systematic Review and Meta-Analysis. Ann Thorac Surg 2018;106:708-14.

52. Aksoy O, Sexton DJ, Wang A, et al. Early surgery in patients with infective endocarditis: a propensity score analysis. Clin Infect Dis 2007;44:364-72.

53. Otome O, Guy S, Tramontana A. A Retrospective Review: Significance of Vegetation Size in Injection Drug Users with Right-Sided Infective Endocarditis. Heart Lung Circ 2016;25:466-70.

54. Manne MB, Shrestha NK, Lytle BW, et al. Outcomes after surgical treatment of native and prosthetic valve infective endocarditis. Ann Thorac Surg 2012;93:489-93.

55. Hilbig A, Cheng A. Infective Endocarditis in the Intravenous Drug Use Population at a Tertiary Hospital in Melbourne, Australia. Heart Lung Circ 2020;29:246-53.

56. Pettersson GB, Coselli JS. AATS Surgical Treatment of Infective Endocarditis Consensus Guidelines Writing Committee Chairs.J Thorac Cardiovasc Surg 2017;153:1241-58.

57. Gaca JG, Sheng S, Daneshmand M. Current outcomes for tricuspid valve infective endocarditis surgery in North America. Ann Thorac Surg 2013;96:1374-81.

58. Dawood MY, Cheema FH, Ghoreishi M. Contemporary outcomes of operations for tricuspid valve infective endocarditis. Ann Thorac Surg 2015;99:539-46.

59. Arbulu A, Thoms NW, Chiscano A, et al. Total tricuspid valvulectomy without replacement in the treatment of Pseudomonas endocarditis. Surg Forum 1971;22:162-4.

60. Arbulu A, Holmes RJ, Asfaw I. Tricuspid valvulectomy without replacement. Twenty years' experience J Thorac Cardiovasc Surg 1991;102:917-22.

61. Robin E, Belamaric J, Thoms NW, et al. Consequences of total tricuspid valvulectomy without prosthetic replacement in treatment of Pseudomonas endocarditis. J Thorac Cardiovasc Surg 1974;68:461-5.

62. Pettersson GB, Hussain ST, Shrestha NK, et al. Infective endocarditis: an atlas of disease progression for describing, staging, coding, and understanding the pathology. J Thorac Cardiovasc Surg 2014;147:1142-1149.e2.

63. Shrestha NK, Jue J, Hussain ST. Injection drug use and outcomes after surgical intervention for infective endocarditis. Ann Thorac Surg 2015;100:875-82. 
64. Thalme A, Westling K, Julander I. In-hospital and longterm mortality in infective endocarditis in injecting drug users compared to non-drug users: a retrospective study of 192 episodes. Scand J Infect Dis 2007;39:197-204.

65. Pomar JL, Mestres CA. Tricuspid valve replacement using a mitral homograft. Surgical technique and initial results. J Heart Valve Dis 1993;2:125-8.

66. Revuelta JM, Bernal JM, Rabasa JM. Partial homograft replacement of mitral valve. Lancet 1994;344:514.

67. Çakıcı M, Özçınar E, Baran Ç, et al. Tricuspid valve

Cite this article as: Nappi F, Spadaccio C, Mihos C, Shaikhrezai K, Acar C, Moon MR. The quest for the optimal surgical management of tricuspid valve endocarditis in the current era: a narrative review. Ann Transl Med 2020;8(23):1628. doi: $10.21037 /$ atm-20-4685 surgery in implantable cardiac electronic device-related endocarditis: Repair or replace? Turk Gogus Kalp Damar Cerrahisi Derg 2018;26:183-91.

68. Ostovar R, Schroeter F, Kuehnel RU, et al. Endocarditis: An Ever Increasing Problem in Cardiac Surgery. Thorac Cardiovasc Surg 2019;67:616-23.

69. Kusztal M, Nowak K. Cardiac implantable electronic device and vascular access: Strategies to overcome problems. J Vasc Access 2018;19:521-7. 